\title{
17a-Hydroxylase Deficiency Diagnosed in Early Infancy Caused by a Novel Mutation of the CYP17A1 Gene
}

\author{
Christina Petri $^{a}$ Stefan A. Wudy ${ }^{d}$ Felix G. Riepe ${ }^{\mathrm{e}}$ Paul-Martin Holterhus ${ }^{\mathrm{e}}$ \\ Jens Siegel $^{b}$ Michaela F. Hartmann ${ }^{d}$ Alexandra E. Kulle ${ }^{e}$ Maik Welzel $^{e}$ \\ Joachim Grötzinger ${ }^{f}$ Ralf L. Schild ${ }^{a}$ Sabine Heger ${ }^{c}$

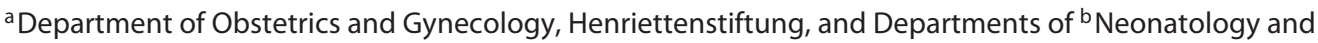 \\ 'General Paediatrics, Diabetology, Endocrinology and Clinical Research, Children's and Youth's Hospital AUF \\ DER BULT, Hannover, ${ }^{d}$ Steroid Research and Mass Spectrometry Unit, Division of Pediatric Endocrinology and \\ Diabetology, Center of Child and Adolescent Medicine, Justus Liebig University Giessen, Giessen, and ${ }^{e}$ Division of \\ Pediatric Endocrinology and Diabetology, Department of Pediatrics, University Hospital of Schleswig-Holstein, and \\ ${ }^{f}$ Institute for Biochemistry, Christian Albrechts University of Kiel, Kiel, Germany
}

\section{Established Facts}

- Mutations in the CYP17A1 gene impair steroid biosynthesis in the adrenals and in the gonads.

- Hydrocortisone replacement is necessary to prevent hypertension and potential occurrence of adrenal crisis.

\section{Novel Insights}

- Early establishment of the diagnosis of $17 \alpha$-hydroxylase deficiency (17OHD) by urinary and plasma steroid profiling.

- Novel mutation in the CYP17A1 gene.

- Proof of diagnosis by gas chromatography mass spectrometry urinary steroid profile from spot urine.

- Plasma steroid determination within the first week of life might miss the diagnosis of 17OHD.

\section{Key Words}

Differences in sex development · 17a-hydroxylase

deficiency . CYP17A1 gene mutation

\section{Abstract \\ Background: Mutations of the CYP17A1 gene cause 17a-hydroxylase deficiency (17OHD) resulting in 46,XY dis- order of sex development, hypertension, hypokalemia and}

absent pubertal development. It is a rare, autosomal recessive form of congenital adrenal hyperplasia (CAH). Patient: We report on a neonate with prenatally determined $46, X Y$ karyotype. At 20 weeks of gestation, lack of development of male external genitalia was noticed. A phenotypically female child was born at 41 weeks of gestation. Results: Postnatal ultrasound revealed testes in both labia majora, an absence of uterus and normal adrenal glands. Steroid hormone analysis in serum revealed low basal levels of cortisol, testoster-

\section{KARGER}

E-Mail karger@karger.com www.karger.com/hrp (c) 2014 S. Karger AG, Base

$1663-2818 / 14 / 0815-0350 \$ 39.50 / 0$
Dr. Sabine Heger

Department of General Paediatrics, Diabetology, Endocrinology and Clinical Research Children's and Youth's Hospital AUF DER BULT

Janusz-Korczak-Allee 12, DE-30173 Hannover (Germany)

E-Mail Heger@hka.de 
one and androstenedione in the presence of massively elevated corticosterone at the age of 2 weeks. The urinary steroid profile from spot urine showed excessive excretion of 17-desoxysteroids, decreased glucocorticoid metabolites and absent C19 steroids, thus proving 17OHD. Molecular analysis identified a novel mutation of the CYP17A1 gene: c.896T>A (p.1299N) in exon 5. Substitution with hydrocortisone was started. The child is raised as a girl and is developing well so far. Conclusion: Herein, we report the unusually early diagnosis of a newborn with the rare CAH form of $170 H D$ allowing an early start of treatment.

(c) 2014 S. Karger AG, Basel

\section{Introduction}

The diagnosis of disorders of sex development (DSD) is disturbing for parents, especially when the anticipation due to the prenatally determined chromosomal sex is not fulfilled during the course of pregnancy or at birth. An early diagnosis is crucial for prognostic means and acceptance of the newborn.

In 46,XY individuals with ambiguous genitalia due to congenital adrenal hyperplasia $(\mathrm{CAH})$, two steroidogenic enzymes might be affected. One of these enzymes is $17 \alpha$-hydroxylase (CYP17A1) and the other one is $3 \beta$-hydroxysteroid type 2 (HSD3B2). They have in common that they affect both adrenal steroidogenesis as well as gonadal steroidogenesis. In addition, deficiency of the electron donor enzyme P450 oxidoreductase (POR) and heme-containing protein cytochrome b5 (CYB5A) have been reported to also cause 46,XY DSD in CAH [1].

Steroid $17 \alpha$-hydroxylase deficiency (17OHD) is a rare form of $\mathrm{CAH}$ and causes about $1 \%$ of all CAH cases. The 508 -amino acid protein is encoded by the cytochrome (CYP) 17A1 gene located on chromosome 10. The enzyme catalyzes two enzymatic steps in steroidogenesis. The first step involves the $17 \alpha$-hydroxylation of pregnenolone and progesterone to 17-hydroxypregnenolone (17OHPreg) and 17-hydroxyprogesterone (17OHP), respectively. The second step results in 17,20 lyase conversion of 17 OHPreg to dehydroepiandrosterone and 17OHP to androstenedione, the latter being irrelevant under normal conditions. Insufficiency of 17a-hydroxylase results in glucocorticoid and sex steroid deficiency [2]. The mineralocorticoid precursors corticosterone and 11-deoxycorticosterone (DOC) accumulate potentially resulting in hypokalemia and hypertension. Both enzymatic steps require electron transfer via the electron donor enzyme POR [3]. In addition to the interaction of CYP17A1 with POR, functional
17,20 lyase activity requires further interaction with the heme-containing protein CYB5A [4].

Since the mineralocorticoid precursor corticosterone exhibits relevant glucocorticoid activity, usually no adrenal crisis occurs except in very stressful situations.

In 1966, Biglieri [5] described the first patient with 17OHD suffering from absence of pubertal development and hypertension. Ten years later, in 1976, the first report on a child with ambiguous genitalia due to $17 \mathrm{OHD}$ diagnosed in early childhood was published [6]. Interestingly, the 3-year-old child having a 46,XY karyotype was misdiagnosed initially as a case of testicular feminization. Because of a semi-comatose condition due to adrenal insufficiency, the diagnosis had to be reevaluated 6 months later [6]. Usually, patients with $17 \mathrm{OHD}$ are noticed during adolescence and adulthood. While genetically female $(46, \mathrm{XX})$ individuals present with primary amenorrhea and hypertension, the sex steroid deficiency results in significant undervirilization and lack of pubertal development in genetically male (46,XY) individuals [7]. Here, we report on a neonate with 46,XY karyotype born with severe undervirilization due to $17 \mathrm{OHD}$.

\section{Case Report}

A 40-year-old primigravid woman was referred to our antenatal clinics at 34 weeks of gestation for further evaluation of a presumed fetal DSD. Prior to admission at 16 weeks of gestation, an amniocentesis had been performed due to advanced maternal age revealing a normal male 46,XY karyotype. At 20 weeks of gestation, a detailed ultrasound examination revealed a fetus presenting female external genitalia but no uterus. A second amniocentesis and genetic examination of the amniotic fluid was performed confirming the male karyotype. Molecular analysis ruled out mutations of the androgen receptor and SRY genes.

The fetus was delivered by emergency caesarean section at 41 weeks of gestation due to heavy vaginal bleeding. At inspection, the neonate presented with normal female external genitalia. Weight, length and head circumference were within the normal range. Small lumps were palpable in the labia majora. No further dysmorphic stigmata were present. Ultrasound examination was suspicious for the presence of testicular tissue in the labia majora. Neither a uterus nor ovaries were detectable by ultrasound investigation.

Serum analysis revealed slightly elevated progesterone $(0.73$ $\mathrm{ng} / \mathrm{ml} ; 0.03-0.53 \mathrm{ng} / \mathrm{ml})$, normal corticosterone $(3.84 \mathrm{ng} / \mathrm{ml}$; $0.09-5.51 \mathrm{ng} / \mathrm{ml})$, low baseline cortisol $(3.69 \mathrm{ng} / \mathrm{ml} ; 2.67-122.34$ $\mathrm{ng} / \mathrm{ml})$, testosterone $(2.88 \mathrm{ng} / \mathrm{dl} ; 6-78 \mathrm{ng} / \mathrm{dl})$ and androstenedione $(2.86 \mathrm{ng} / \mathrm{dl} ; 2.9-34 \mathrm{ng} / \mathrm{dl})$ levels at the age of 5 days. At the age of 2 weeks, progesterone increased, corticosterone was highly elevated, while cortisol and androgens remained low (table 1). In particular, there was only marginal cortisol but an extreme corticosterone response $(310 \mathrm{ng} / \mathrm{ml})$ to adrenocorticotropic hormone (ACTH) (table 1). At the age of 6 weeks, the urinary steroid pro- 
Table 1. Summary of clinical and hormonal findings at different ages

\begin{tabular}{|c|c|c|c|c|}
\hline & \multicolumn{2}{|c|}{ Before treatment } & \multicolumn{2}{|c|}{ After initiation of treatment } \\
\hline Age: & 2 weeks & 6 weeks & 7 months & 2.0 years \\
\hline \multirow{2}{*}{\multicolumn{5}{|c|}{ Hydrocortisone therapy, }} \\
\hline & & & 9 & 12.7 \\
\hline Height, cm & 53 & & 68.8 & 88.3 \\
\hline Weight, kg & 3.3 & & 7.9 & 12.6 \\
\hline BMI & 12.2 & & 16.8 & 16.1 \\
\hline \multicolumn{5}{|l|}{ Serum parameters } \\
\hline $\mathrm{Na}+, \mathrm{mmol} / \mathrm{l}$ & $137(1$ & & & 145 \\
\hline $\mathrm{K}+, \mathrm{mmol} / \mathrm{l}$ & $5.2(3$ & & & 5.1 \\
\hline $\mathrm{LH}, \mathrm{mIU} / \mathrm{ml}$ & $6.6(<$ & & & \\
\hline $\mathrm{FSH}, \mathrm{mIU} / \mathrm{ml}$ & $1.9(<$ & & & \\
\hline ACTH, ng/l & $106.2(1$ & & & \\
\hline Preg, ng/ml & $2.51(0$ & & & \\
\hline $\mathrm{P}, \mathrm{ng} / \mathrm{ml}$ & $0.97(0$ & & & $0.35(0.04-0.14)$ \\
\hline $\mathrm{DOC}, \mathrm{ng} / \mathrm{ml}$ & $0.07(0$ & & & $0.38(0.06-0.25)$ \\
\hline $\mathrm{B}, \mathrm{ng} / \mathrm{ml}$ & $100.27(0$ & & & $11.9(0.09-4.25)$ \\
\hline Aldo, ng/ml & & & & 0.17 \\
\hline 17OHPreg, ng/ml & $2.17(0$ & & & \\
\hline $17 \mathrm{OHP}, \mathrm{ng} / \mathrm{ml}$ & $0.49(0$ & & & $<0.03(0.06-0.57)$ \\
\hline $11 \mathrm{~S}, \mathrm{ng} / \mathrm{ml}$ & $0.09(0$ & & & \\
\hline $\mathrm{F}, \mathrm{ng} / \mathrm{ml}$ & $5.86(2$ & & & $26.4(18.07-221.6)$ \\
\hline $\mathrm{F}$ after $\mathrm{ACTH}, \mathrm{ng} / \mathrm{ml}$ & 17.45 & & & \\
\hline DHEA, ng/ml & $0.29(0$ & & & \\
\hline DHEAS, ng/ml & $30.26(2$ & & & \\
\hline Andro, ng/dl & $8.58(1$ & & & $<2.9(2.9-23)$ \\
\hline Testo, ng/dl & $2.88(1$ & & & $7(2.9-20)$ \\
\hline \multicolumn{5}{|l|}{ Urinary parameters } \\
\hline $\mathrm{P} 5 \mathrm{D} / \mathrm{Fs}$ & & $1.10(<0.02)$ & $0.00(<0.02)$ & $0.00(<0.01)$ \\
\hline $\mathrm{Bs} / \mathrm{Fs}$ & & $4.02(<0.29)$ & $1.38(<0.29)$ & $1.07(<0.15)$ \\
\hline 16OH-P5/16OH-DHA & & $149(<1)$ & not indicative & not indicative \\
\hline
\end{tabular}

Preg = Pregnenolone; $\mathrm{P}$ = progesterone; $\mathrm{B}=$ corticosterone; Aldo = aldosterone; $11 \mathrm{~S}=11$-deoxycortisol; $\mathrm{F}=$ cortisol; DHEA = dehydroepiandrosterone; DHEAS = dehydroepiandrosterone sulfate; Andro = androstenedione; Testo = testosterone; $\mathrm{LH}=$ luteinizing hormone; $\mathrm{FSH}=$ follicle-stimulating hormone; $\mathrm{P} 5 \mathrm{D}=$ pregnenediol (main metabolite of pregnenolone); Fs = sum of major cortisol metabolites (i.e. tetrahydrocortisone, tetrahydrocortisol and 5a-tetrahydrocortisol); Bs = sum of major corticosterone metabolites (i.e. tetrahydro-11-dehydrocorticosterone, tetrahydrocorticosterone and 5a-tetrahydrocorticosterone); 16OH-P5 = 16a-hydroxypregnenolone; $16 \mathrm{OH}-\mathrm{DHA}=16 a$-hydroxydehydroepiandrosterone. The metabolic precursor/product ratio $\mathrm{P} 5 \mathrm{D} / \mathrm{Fs}$ is indicative of 17-hydroxylase function, whereas the ratio $16 \mathrm{OH}-\mathrm{P} 5 / 16 \mathrm{OH}-\mathrm{DHA}$ characterizes 17,20 -lyase function. Limits of normal ranges are given in parentheses.

file - assessed by gas chromatography mass spectrometry (GCMS) - showed excessive excretion of 17-deoxysteroids, decreased glucocorticoid metabolites and absent C19 steroids confirming 17OHD (table 1).

Molecular analysis identified a novel mutation of the CYP17A1 gene c.896T >A (p.1299N) in exon 5 (fig. 1). In silico analysis utilizing PolyPhen, SIFT and Mutation T@sting revealed a deleterious effect of the mutant [PolyPhen score 0.998 (computational range 0-1), SIFT 'not tolerated', Mutation T@sting score 194 (computational range 0-215)].

Replacement therapy with hydrocortisone was started. The patient is raised as a girl. Hydrocortisone treatment was monitored primarily by urinary steroid profiles demonstrating normalization of the excreted steroids. The determination of serum steroids at the age of 2 years revealed increased biosynthesis of mineralocorticoid precursors, indicating that in stressful situations, such as painful blood withdrawal, a stimulation of precursors is possible.

At the age of 2.5 years, the child is growing well along the 50th centile for weight and height according to the reference growth chart for girls [8]. Blood pressure levels before and after initiation of treatment were always within the normal range.

The parents were healthy and not consanguineous, but refused molecular testing. 


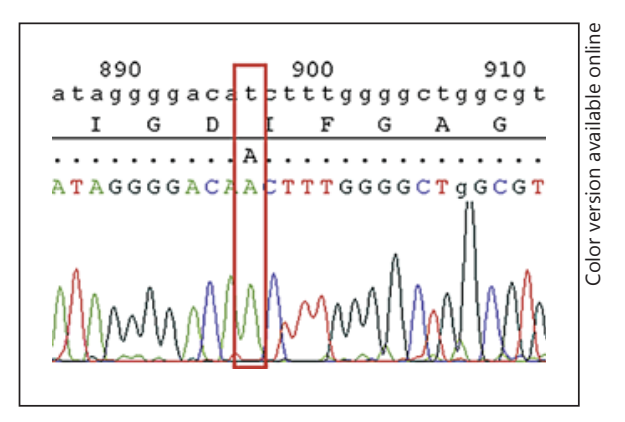

Fig. 1. Molecular analysis of the CYP17A1 gene. Rectangle indicates the homozygous nucleotide exchange form thymine to adenine at position 896 in exon 5.

\section{Methods}

\section{GC-MS Urinary Steroid Profiling}

Steroid profiles were analyzed using quantitative data generated by GC-MS analysis as described previously [9]. In brief, free and conjugated urinary steroids were extracted by solid-phase extraction (SPE), and conjugates were enzymatically hydrolyzed. After recovery of hydrolyzed steroids by SPE, known amounts of internal standards were added to each extract before formation of methyloxime-trimethylsilyl ethers. GC was performed using an Optima-1 fused silica column (Macherey-Nagel, Dueren, Germany) housed in an Agilent Technologies 6890 series GC that was directly interfaced to an Agilent Technologies 5973 mass selective detector.

\section{Plasma Steroid Profiling}

Mineralocorticoids, glucocorticoids and androgens in plasma were measured by ultra-pressure liquid chromatography tandem mass spectrometry (UPLC-MS/MS, Waters Quattro Premier) according to a previously described method [10]. In brief, aliquots of samples, calibrators and controls were extracted by SPE using $\mathrm{Oa}-$ sis MAX SPE system plates (Waters, Milford, Mass., USA). Deuterium-labelled steroids were used as internal standards. The UPLCMS/MS system was used in multiple reaction monitoring mode (MRM), and steroids were measured in positive ion mode except aldosterone which was measured in negative mode. For each hormone, two different MRM transitions were monitored. The limit of quantification was between $0.1 \mathrm{nmol} / \mathrm{l}$ for $17-\mathrm{OHP}$ and $2 \mathrm{nmol} / \mathrm{l}$ for cortisol. The intra- and interassay coefficient of variations for replicate quality controls for different concentrations ranges between 2.4 and $9.7 \%$. Total run time for the assay was $5 \mathrm{~min}$. Reference data for pregnenolone are published in Riepe et al. [11].

\section{Mutation Analysis}

DNA sequencing analysis was carried out after obtaining informed consent from the parents. Genomic DNA was extracted from peripheral blood leukocytes using a DNA blood and cell culture kit (QIAGEN GmbH, Hilden, Germany). The mutation analysis was performed after PCR of the CYP17A1 gene in five fragments by direct DNA sequencing of the complete coding region of the CYP17A1 gene, including the intron-exon boundaries. The samples were electrophoresed on an automated ABI PRISM 310
Sequencer (Applied Biosystems Inc., Weiterstadt, Germany) and analyzed with the ABI SeqScape 1.1 software (Applied Biosystems) [12].

Multiplex ligation-dependent probe amplification (MLPA) [13] was performed according to the manufacturer's recommendations using the SALSA ${ }^{\circledR}$ MLPA ${ }^{\circledR}$ P334-A2 probemix 'Gonadal Development Disorder' (MRC-Holland, Amsterdam, the Netherlands). This method is able to detect deletions or duplications of the first 7 exons of the CYP17A1 gene. A patient with a known deletion of exons 1-6 served as positive control.

We performed an in silico analysis using three different types of software: PolyPhen (http://genetics.bwh.harvard.edu/pph/), SIFT (http://sift.jcvi.org/) and Mutation T@sting (http://www. mutationtaster.org/). These bioinformatics tools enable highthroughput prediction of the potential impact of residue changes and large-scale polymorphism analyses. PolyPhen and Mutation T@sting predict the possible impact of an amino acid substitution on the structure and function of a human protein using straightforward physical and comparative considerations, whereas SIFT predicts the functional importance of amino acid substitutions based on the alignment of orthologous and/or paralogous protein sequences [14-16].

The impact of the new mutation on protein conformation was studied using the three-dimensional structure of human CYP17A1 (PDB code 3RUK) [17]. The structural representation was generated using the Ribbons software [18].

\section{Discussion}

In the present case, the diagnosis of $17 \mathrm{OHD}$ was established at the very early age of 2 weeks. The absence of the development of male external genitalia in a 46,XY individual noticed prenatally caused major concern, resulting in prenatal exclusion of mutations in the androgen receptor gene and SRY gene. The postnatal hormonal workup at 2 weeks revealed only in part a typical hormonal phenotype of combined deficiency of $17 \alpha$-hydroxylation and 17,20-lyase activity. On the one hand, plasma steroids showed elevated levels for progesterone and corticosterone, while cortisol and androgens were low, indicating 17OHD. On the other hand, pregnenolone and DOC were not elevated at this time. At the age of 6 weeks, the metabolic precursor/product ratios indicative of 17a-hydroxylase activity as well as 17,20-lyase activity [19,20] determined by urinary steroid profile were very high, proving the diagnosis of CYP17A1 deficiency [21]. It seems noteworthy that both plasma steroid analysis and urinary steroid analysis showed the functional defect; however, urinary steroid analysis is less invasive and would have been sufficient to establish the diagnosis alone. Interestingly, the plasma steroid analysis at 5 days of age was not conclusive for $17 \mathrm{OHD}$. This may be due to a low ACTH drive because of the conversion of mater- 


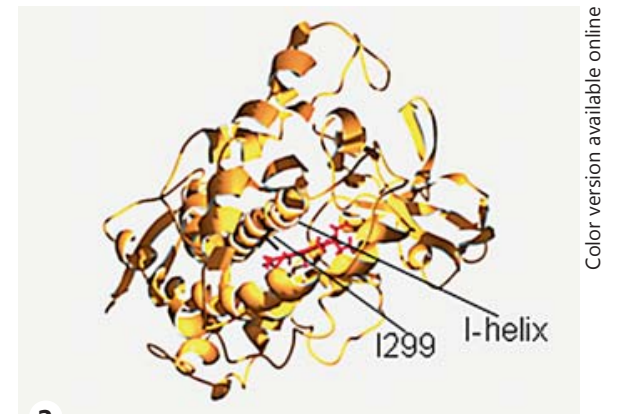

a

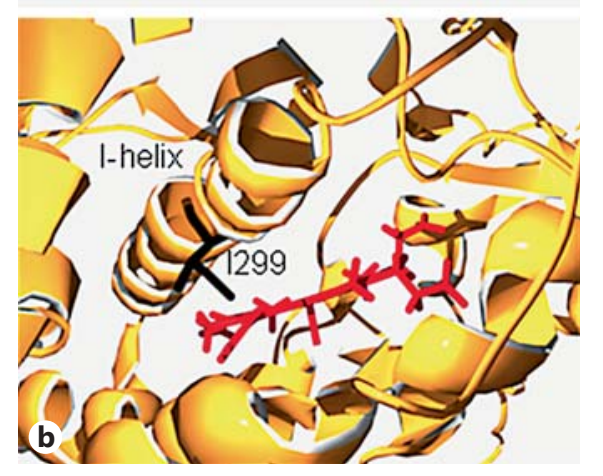

Fig. 2. CYP17A1 three-dimensional structural model. a Total view of the CYP17A1 protein structure with the central I-helix and the depicted residue I299. The heme group is depicted in red. b Isoleucine 299 is part of the central hydrophobic cluster of the I-helix and in close contact to the heme group. The change to the polar amino acid residue asparagine will disturb the hydrophobic environment and hereby the catalytic activity and substrate binding within the substrate-binding pocket. Colors refer to the online version only.

nally derived cortisone, which is converted to cortisol within the first days of life [22]. Therefore, the very early steroid determination in plasma might miss the correct diagnosis of $17 \mathrm{OHD}$. There are 2 other differential diagnoses that could have caused a similar hormonal profile. One is CYB5 [23], which typically leads to isolated androgen deficiency without affecting glucocorticoid biosynthesis. The other is PORD, which typically is associated with elevated 17OHP $[1,24]$. However, 17OHP levels were not increased in our patient. In addition, the absence of elevated metabolic parameters for 21-hydroxylase deficiency in the urinary steroid profile excluded PORD in this particular case.

In the child reported here, a novel mutation of the of the CYP17A1 gene c.896T>A (p.1299N) in exon 5 was found. To date, over 90 mutations of the CYP17A1 gene have been reported (www.hgmd.cf.ac.uk/ac/gene. php?gene $=$ CYP17A1). About $80 \%$ contain missense mu- tations and small deletions. Homozygous mutations are usually found in consanguineous families. Taken into consideration that $17 \mathrm{OHD}$ is a very rare disease with the frequency of heterozygous individuals virtually impossible to estimate, it is surprising that the parents of the child investigated in this study were reported not to be consanguineous. Unfortunately, we were not able to analyze the genomic DNA of the parents. Therefore, compound heterozygosity of this mutation combined with a partial or complete gene deletion is an alternative explanation for the molecular finding. In our case, 3 independent MLPA experiments excluded a gene deletion confirming a homozygous mutation. Although the functional relevance of the mutation reported in our patient has not been experimentally proven, the clinical picture and distinct biochemical results show the functional relevance of the mutation. I299 is situated in the I-helix and is hereby part of the hydrophobic core of the substrate-binding pocket of CYP17A1. The substrate-binding pocket of CYP17 is lined by the heme group, which forms the bottom of the pocket; the top is constituted by I-helix running along one edge of the heme ring; strands 4 and 5 of $\beta$-sheet 1 , opposite the I-helix; I112 in the B'-C loop to one side; the loop behind the K-helix on the other side, and finally, V482 and V483, which form a turn in $\beta$-sheet 3 . Therefore, the side chain of amino acid residue I299 is in direct contact with the heme group and the substrate (fig. 2). The exchange of hydrophobic isoleucine with the polar amino acid residue asparagine will disturb the hydrophobic environment and hereby the catalytic activity or substrate binding within the active side of the enzyme.

\section{Conclusion}

Prenatal information on the fetal sex is becoming available more frequently due to the performance of prenatal screening for other diseases such as numeric chromosomal imbalances. This provides an opportunity to detect and treat rare congenital adrenal diseases before they may cause severe harm to the child.

Our case demonstrates the diagnostic challenges in a patient with 46,XY karyotype and severe male undervirilization. GC-MS urinary steroid profiling, a noninvasive diagnostic procedure of enormous diagnostic potential, proved the correct adrenal enzyme defect from spot urine. In many cases, the diagnosis is made later in life when patients may present with absence of pubertal development, primary to secondary amenorrhea or hypertension. In our view, an early diagnosis is essential to avoid 
hypokalemia and hypertension and in order to prevent fatal adrenal crisis. Although the latter might be rare, it has been reported by Heremans et al. [6] in 1976. One may even speculate that this condition might be the cause of some unexplained cases of sudden infant death. Therefore, patients should receive replacement therapy with hydrocortisone early and be equipped with an emergency health card.

\section{Acknowledgment}

We gratefully thank Gisela Hohmann for performing sequencing and MLPA analysis and Diana Deeke for linguistic advice.

\section{References}

1 Krone N, Arlt W: Genetics of congenital adrenal hyperplasia. Best Pract Res Clin Endocrinol Metab 2009;23:181-192.

-2 Geller DH, Auchus RJ, Mendonca BB, Miller WL: The genetic and functional basis of isolated 17,20-lyase deficiency. Nat Genet 1997; 17:201-205

3 Arlt W, Walker EA, Draper N, Ivison HE, Ride JP, Hammer F, Chalder SM, BoruckaMankiewicz M, Hauffa BP, Malunowicz EM, Stewart PM, Shackleton CH: Congenital adrenal hyperplasia caused by mutant $\mathrm{P} 450$ oxidoreductase and human androgen synthesis: analytical study. Lancet 2004;363:2128-2135.

4 Auchus RJ, Lee TC, Miller WL: Cytochrome b5 augments the 17,20-lyase activity of human P450c17 without direct electron transfer. J Biol Chem 1998;273:3158-3165.

5 Biglieri EG: 17 alpha-Hydroxylase deficiency: 1963-1966. J Clin Endocrinol Metab 1997;82: 48-50.

-6 Heremans GF, Moolenaar AJ, van Gelderen HH: Female phenotype in a male child due to 17-alpha-hydroxylase deficiency. Arch Dis Child 1976;51:721-723.

7 Rosa S, Duff C, Meyer M, Lang-Muritano M, Balercia G, Boscaro M, Topaloglu AK, Mioni R, Fallo F, Zuliani L, Mantero F, Schoenle EJ, Biason-Lauber A: P450c17 deficiency: clinical and molecular characterization of six patients. J Clin Endocrinol Metab 2007;92: 1000-1007.

8 Kromeyer-Hauschild K, Wabitsch M, Kunze D, Geller F, Geiss HC, Hesse V, von Hippel A, Jaeger U, Johnsen D, Korte W, Menner K, Mueller G, Mueller JM, Niemann-Pilatus A, Remer T, Schaefer F, Wittchen HU, Zabransky S, Zellner K, Ziegler A, Hebebrand J: Percentiles of body mass index in children and adolescents evaluated from different regional German studies (in German). Monatsschr Kinderheilkd 2001;149:807-818.
9 Wudy SA, Hartmann MF, Remer T: Sexual dimorphism in cortisol secretion starts after age 10 in healthy children: urinary cortisol metabolite excretion rates during growth. Am J Physiol Endocrinol Metab 2007;293:E970E976.

10 Kulle AE, Welzel M, Holterhus PM, Riepe FG: Implementation of a liquid chromatography tandem mass spectrometry assay for eight adrenal C-21 steroids and pediatric reference data. Horm Res Paediatr 2013;79:22-31.

11 Riepe FG, Wonka S, Partsch CJ, Sippell WG: Automated chromatographic system for the simultaneous measurement of plasma pregnenolone and 17-hydroxypregnenolone by radioimmunoassay. J Chromatogr B Biomed Sci Appl 2001;763:99-106.

12 Dhir V, Reisch N, Bleicken CM, Lebl J, Kamrath C, Schwarz HP, Grotzinger J, Sippell WG, Riepe FG, Arlt W, Krone N: Steroid 17alpha-hydroxylase deficiency: functional characterization of four mutations (A174E, V178D, R440C, L465P) in the CYP17A1 gene. J Clin Endocrinol Metab 2009;94:3058-3064.

13 Schouten JP, McElgunn CJ, Waaijer R, Zwijnenburg D, Diepvens F, Pals G: Relative quantification of 40 nucleic acid sequences by multiplex ligation-dependent probe amplification. Nucleic Acids Res 2002;30:e57.

14 Adzhubei IA, Schmidt S, Peshkin L, Ramensky VE, Gerasimova A, Bork P, Kondrashov AS, Sunyaev SR: A method and server for predicting damaging missense mutations. Nat Methods 2010;7:248-249.

15 Kumar P, Henikoff S, Ng PC: Predicting the effects of coding non-synonymous variants on protein function using the SIFT algorithm. Nat Protoc 2009;4:1073-1081.

-16 Schwarz JM, Rodelsperger C, Schuelke M, Seelow D: MutationTaster evaluates diseasecausing potential of sequence alterations. Nat Methods 2010;7:575-576.
17 DeVore NM, Scott EE: Structures of cytochrome P450 17A1 with prostate cancer drugs abiraterone and TOK-001. Nature 2012;482: 116-119.

18 Kraulis PJ: Molscript - a program to produce both detailed and schematic plots of protein structures. J Appl Crystallogr 1991;24:946950.

19 Tiosano D, Navon R, Flor O, Knopf C, Hartmann MF, Wudy SA, Yakhini Z, Hochberg Z: A steroid metabolomic approach to $17 \mathrm{a}$-hydroxylase/17,20 lyase deficiency. Metabolomics 2010;6:417-426.

20 Wudy SA, Hartmann MF, Draper N, Stewart PM, Arlt W: A male twin infant with skull deformity and elevated neonatal 17-hydroxyprogesterone: a prismatic case of $\mathrm{P} 450$ oxidoreductase deficiency. Endocr Res 2004;30: 957-964.

21 Tiosano D, Knopf C, Koren I, Levanon N, Hartmann MF, Hochberg Z, Wudy SA: Metabolic evidence for impaired 17alpha-hydroxylase activity in a kindred bearing the E305G mutation for isolate 17,20-lyase activity. Eur J Endocrinol 2008; 158:385-392.

22 Dotsch J, Hohenberger I, Riepe FG, Sippell WG, Dorr HG: Serum cortisol and cortisone levels in newborns with congenital adrenal hyperplasia before the start of therapy. J Endocrinol Invest 2005;28:413-416.

23 Idkowiak J, Randell T, Dhir V, Patel P, Shackleton CHL, Taylor NF, Krone N, Arlt W: A missense mutation in the human cytochrome b5 gene causes 46,XY disorder of sex development due to true isolated 17,20 lyase deficiency. J Clin Endocrinol Metab 2012;97:E465E475.

24 Fluck CE: Congenital adrenal hyperplasia owing to 17alpha-hydroxylase/17,20 lyase and p450 oxidoreductase deficiencies. Adv Exp Med Biol 2011;707:3-5. 